\title{
Bedside Shift Report Improves Patient SAFETY AND NurSE ACCOUNTABILITY
}

\author{
Author: Stephanie J. Baker, RN, CEN, MBA, San Diego, CA \\ Section Editor: Nancy McGowan, RN, PhD, CEN
}

W hy bedside shift report? The short answer: Patient safety.

The truth is, thousands of patients are cared for every day in US emergency departments, resulting in thousands of shift changes and thousands of opportunities for error. According to the Institute of Medicine's report To Err is Human: Building a Safer Health System, between 44,000 and 98,000 people die in US hospitals each year because of preventable health care errors. ${ }^{1}$

Even greater are the numbers of preventable errors that do not result in death but lead to acute or chronic illness, injury, and/or disability. Financial costs from errors are also substantial and include lost income, reduced productivity, increased health care costs, and inflated health insurance premiums. ${ }^{1}$

The emergency department is also a high-risk environment in which additional safety factors must be considered. The National Quality Forum identified these as multiple individuals involved in the care of a single patient; patients with high-acuity illness or injury; rapid health care decisions under severe time constraints; high volume of patients and unpredictable patient flow; barriers to communication with patients, families, and other health care professionals; and interactions with multiple types of diagnostic and/or treatment technology. ${ }^{2}$

\section{Other Benefits}

Bedside shift report is also an excellent way to build employee teamwork, ownership, and accountability. In addition, it responds directly to a number of the Joint

Stephanie J. Baker, Member, Chapter 288, is a Coach, Account Leader, and National Speaker, Studer Group, Gulf Breeze, FL.

For correspondence, write: Stephanie J. Baker, RN, CEN, MBA, Studer Group, 913 Gulf Breeze Pkwy, Gulf Breeze, FL 32561; E-mail: stephanie. baker@studergroup.com.

J Emerg Nurs 2010;36:355-8.

Available online 14 May 2010.

$0099-1767 / \$ 36.00$

Copyright (C) 2010 Published by Elsevier Inc on behalf of the Emergency

Nurses Association.

doi: 10.1016/j.jen.2010.03.009
Commission's National Patient Safety Goals, including goal 1 ("improve the accuracy of patient identification") because we check the patient's armband and ask the patient his or her name and birth date as identifiers, goal $2 \mathrm{E}$ ("improve the effectiveness of communication among caregivers: managing hand-off communications," with particular attention to ensuring the opportunity for asking and responding to questions), and goal 13 ("encourage patients' active involvement in their own care as a patient safety strategy." $)^{3}$

\section{What Is in It for Staff}

Although it sounds simple, staff may be resistant to this process for any number of reasons. However, here is the really wonderful thing: Bedside shift report drives staff ownership and accountability. If you have ever heard staff comment, "You should see the way the night shift left their rooms!" or "The intravenous line is dry, his sheets are wet, and there are two full urinals on the Mayo stand!," you will appreciate the way bedside shift report creates ownership and accountability. Here is what is in it for staff:

- Opportunity for real-time conversations. If I go into the room and see that the last nurse has left it in disarray, I can say, “Kim, why don't you empty the urinals while I check the patient and update the whiteboard?" If I, as a staff nurse, understand that bedside report is an expectation and understand that someone is going to be checking both my patients and my rooms, as well as verifying my charts, then I am going to be more likely to ensure everything is in order before that shift change.

- More time. Although you might hear initial staff concerns that it will "take too long" or that they "don't have time," the reality is that nurses will be with the patient for 3 to 5 minutes while they physically check the patient, update the whiteboard, and do an environmental check (e.g., Is the intravenous line patent? Are the side rails up? Does the patient have the call light within reach?). Because it is a quick physical check on the patient, the nurse can ensure the patient's room is in good condition and the patient is safe and then check on other patients. 


\section{ED Bedside Shift Report Using SBAR(T) Format}

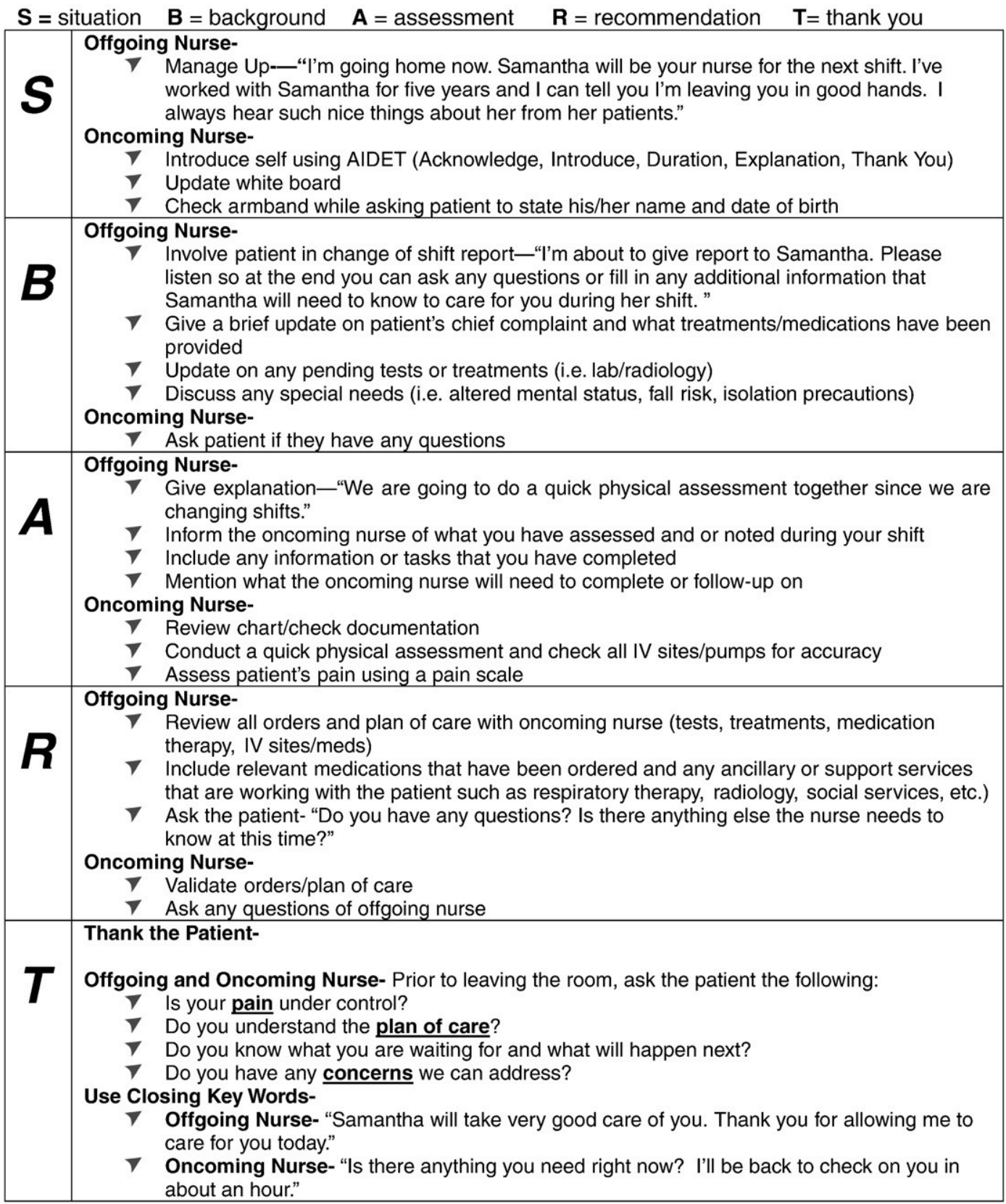

\section{FIGURE 1}

ED bedside shift report using $\mathrm{SBAR}(\mathrm{T})$ format. IV, intravenous; meds, medications.

- A way to transfer trust. Bedside shift report is a warm handoff, allowing the patient to say goodbye and thank the nurse who has cared for him or her during his or her stay.
- Mentoring for new nurses. It is good discipline for another nurse to review a new nurse's documentation, physically see their patients, and review their assessments, medication therapy, and environmental factors 


\section{Sample Bedside Report Dashboard}

\begin{tabular}{|c|c|c|c|c|c|c|}
\hline & n size & $\begin{array}{c}\text { Nurse took time to } \\
\text { listen }\end{array}$ & $\begin{array}{l}\text { Nurses informative } \\
\text { re: treatments }\end{array}$ & Informed about delays & $\begin{array}{l}\text { Staff cared about } \\
\text { you as a person }\end{array}$ & $\begin{array}{c}\text { How well pain was } \\
\text { controlled }\end{array}$ \\
\hline Baseline & & $50 \%$ & $58 \%$ & $28 \%$ & $45 \%$ & $58 \%$ \\
\hline Goal- In Percentile Rank & & $50 \%$ & $50 \%$ & $50 \%$ & $50 \%$ & $50 \%$ \\
\hline \multicolumn{7}{|l|}{ Week of: } \\
\hline $7 / 29-8 / 4$ & 13 & $51 \%$ & $76 \%$ & $93 \%$ & $90 \%$ & $97 \%$ \\
\hline $8 / 5-8 / 11$ & 11 & $87 \%$ & $57 \%$ & $58 \%$ & $66 \%$ & $8 \%$ \\
\hline $8 / 12-8 / 18$ & 11 & $71 \%$ & $81 \%$ & $19 \%$ & $21 \%$ & $50 \%$ \\
\hline $8 / 19-8 / 25$ & 11 & $87 \%$ & $87 \%$ & $6 \%$ & $72 \%$ & $67 \%$ \\
\hline $8 / 28-9 / 1$ & 8 & $14 \%$ & $81 \%$ & $25 \%$ & $26 \%$ & $75 \%$ \\
\hline $9 / 2-9 / 8$ & 11 & $93 \%$ & $93 \%$ & $78 \%$ & $88 \%$ & $91 \%$ \\
\hline $9 / 9-915$ & 1 & $72 \%$ & $61 \%$ & $69 \%$ & $81 \%$ & $64 \%$ \\
\hline $9 / 16-9 / 22$ & 1 & $62 \%$ & $99 \%$ & $99 \%$ & $99 \%$ & $81 \%$ \\
\hline $9 / 23-9 / 29$ & 3 & $90 \%$ & $99 \%$ & $99 \%$ & $99 \%$ & $99 \%$ \\
\hline $9 / 30-10 / 6$ & 7 & $76 \%$ & $80 \%$ & $92 \%$ & $82 \%$ & $76 \%$ \\
\hline $10 / 7-10 / 13$ & 1 & $99 \%$ & $99 \%$ & $91 \%$ & $99 \%$ & $99 \%$ \\
\hline
\end{tabular}

Baseline $=$ May - July

Report $=$ Pt response by Date of Discharge. Note: Weekly results may change over time

FIGURE 2

Sample bedside report dashboard. Pt, patient.

every 12 hours. Who knows? A new nurse could be so busy focusing on her clinical skills that she forgets to think about patient comfort measures.

\section{What Is in It for Patients}

Bedside shift report increases patients' involvement in their plan of care in many ways. They see and hear from the team of professionals who are providing their care. As a result, they feel more comfortable asking questions or voicing concerns; they are reassured that everyone is receiving the necessary report about what is going on with them; they feel more informed about their care, which makes them less anxious and more compliant with the plan of care; they are more satisfied because they know that things are being monitored throughout the shift; they know who their nurse is on every shift; and bedside shift report reduces the perception that "no one is around" during shift change when sentinel events are more likely to occur.

\section{Before You Begin}

However, before attempting to implement this process, be sure you have already hardwired leader rounding on staff and leader rounding on patients to ensure that your staff are engaged and that you have a process in place to obtain feedback from patients. (See previous articles on rounding for outcomes and discharge phone calls. ${ }^{4,5}$ ) You will also want to discuss with staff why you are implementing bedside shift report. Review the process and gain agreement. Finally, verify outcomes through leader rounding on patients.

The key to successfully hardwiring bedside report is to implement processes that clearly define the responsibility from one caregiver to another, standardize the communication process, and allow for an interactive exchange between the parties involved. Bedside shift report decreases the potential for near misses through a transfer of responsibility and trust and by using standardized communication.

\section{How to Implement Bedside Shift Report}

Bedside shift report is meant to be fast. Before entering the patient's room, the incoming nurse will look at the chart and go over the medical history, treatments, and anything pending while at the desk ... just like he or she normally does. Then, the outgoing and incoming nurses will go to the bedside together, where the outgoing nurse "manages up" — positions in a positive light — the incoming nurse and introduces him or her.

The incoming nurse's role is to ask the patient his or her name and date of birth and to check the armband for safety and introduce himself or herself. He or she should update the whiteboard in the room and double-check pumps as well as all intravenous medications for accuracy and the patient's safety.

Before bedside shift report, advise and educate the patient that it will be occurring. (I know some emergency departments that even provide patients with a letter to explain and manage up the process.) 
Then, use the SBAR (situation-background-assessment-recommendation) communication technique. It provides a framework for communication between members of your health care team. SBAR is an easy-to-remember and concrete mechanism useful for framing any conversation, including those held in front of the patient. This technique facilitates an easy, focused way to set expectations and relay important information (Figure 1).

\section{Tips for Success}

- Be sensitive to privacy and information shared in front of the patient. Use key words to let the patient know you will maintain his or her privacy and keep his or her information safe. Discuss sensitive information away from the patient's bedside to maintain confidentiality.

- Educate the incoming nursing team about bedside shift report if they are float or registry personnel.

- Exclude opinions. Report is a time for facts. If a nurse is unhappy with the patient (or physician caring for the patient), the bedside report is not the time to vent. Criticism makes the nurse appear less credible.

- Avoid putting a nurse on the spot in front of the patient and/or family.

If the incoming nurse has a question or needs clarification about a sensitive issue, wait until after bedside shift report is complete.

\section{Track and Follow-up}

Just as we recommend when implementing other processes (e.g., rounding for outcomes, discharge phone calls), you will want to formalize training of staff on bedside shift report and ask an evaluator to complete a competency assessment to ensure standardization and compliance. Then, report back wins and opportunities regularly to staff at huddles and stand-up meetings using results from the bedside report dashboard (Figure 2).

\section{REFERENCES}

1. Institute of Medicine. To Err is Human: Building a Safer Health System. Washington, DC: National Academies Press; 2004.

2. Kizer KW. Patient safety: A call to action: A consensus statement from the National Quality Forum. MedGenMed. 2001;3(2):10. http://www.med scape.com/mgmhome?src-hdr. Accessed May 2009.

3. The Joint Commission. Joint Commission 2009 National Patient Safety Goals. Oakbrook Terrace; Dec. 29, 2009.

4. Baker SJ. Rounding for outcomes: an evidence-based tool to improve nurse retention, patient safety, and quality of care. J Emerg Nurs. 2010;35:162-4

5. Baker SJ. Post-visit phone calls save lives, improve clinical outcomes, and reduce re-admissions. J Emerg Nurs. 2010;36:256-9.

Submissions to this column are encouraged and may be sent to Nancy McGowan, RN, PhD, CEN

Mcgowann@uthscsa.edu 